\title{
A desindustrialização na região Sul
}

\author{
Deindustrialization in the South region of Brazil
}

José Alderir Silva [l]

\section{Resumo}

Este estudo objetiva analisar a evolução da indústria de transformação no Brasil com ênfase na região Sul no período 2002-2014, de modo que seja possível observar a contribuição sulista no processo de desindustrialização do País. Para isso, serão utilizados como forma de análise os indicadores clássicos da desindustrialização. Com efeito, foi observado que a indústria da região Sul perdeu participação em termos de valor adicionado e de emprego nos indicadores nacionais, porém, a manifestação da desindustrialização pode ser confirmada apenas a partir da composição da estrutura produtiva regional. Nesse sentido, constatou-se a perda de participação da indústria de transformação combinada com a desconcentração da produção/emprego industrial sulista, o que configura um processo de desindustrialização regional progressivo e positivo nessa região.

Palavras-chave: desindustrialização; economia regional; Rio Grande do Sul.

\begin{abstract}
This study analyzes the evolution of the manufacturing industry in Brazil focusing on the South region in the period 2002-2014, so that it is possible to observe the southern contribution to the country's deindustrialization process. For this, the classic indicators of deindustrialization will be used as a form of analysis. Indeed, it was found that the industry of the South has lost share in terms of value added and employment in national indicators, but the manifestation of deindustrialization can only be confirmed by the composition of the regional productive structure. In this sense, the loss of share of the manufacturing industry was verified, combined with the deconcentration of the southern industrial production/employment, which constitutes a progressive and positive deindustrialization process in this region.
\end{abstract}

Keywords: deindustrialization; regional economy; Rio Grande do Sul. 


\section{Introdução}

Desde os anos de 1980, a indústria de transformação no Brasil tem apresentado uma perda sistemática de participação no PIB, o que gerou um intenso debate no âmbito acadêmico sobre um possível processo de desindustrialização na economia brasileira.

Entretanto, apesar dos significativos avanços, a discussão sobre esse processo pouco avançou no âmbito regional, deixando a entender que a desindustrialização ocorre de forma homogênea nas regiões e estados. Contudo, isso não é verdade.

Assim, com o objetivo de contribuir com o debate, mas chamando a atenção para o aspecto regional do processo de desindustrialização, o presente estudo busca analisar a evolução da indústria de transformação na região Sul e, por sua vez, em seus estados no período 2002-2014. Além disso, ao realizar esta análise, busca-se observar se o processo de desindustrialização em vigor no Brasil pode ser explicado pela trajetória da indústria de transformações na região Sul.

Para isso, serão utilizados, como instrumento de análise, os indicadores clássicos da desindustrialização. Com efeito, ao realizar-se a análise, foi observado que a indústria de transformação da região Sul perdeu participação, em termos de valor adicionado ou de emprego, nos indicadores nacionais na última década. Porém, essa perda tem se concentrado no estado de São Paulo, o que configura um processo de desindustrialização regional regressiva "positiva", conforme os conceitos desenvolvidos por Silva (2017), já que também ocorreu uma desconcentração da produção industrial na região.
A estrutura deste paper está dividida em mais quatro seções, além desta introdução. $A$ primeira seção aborda o debate sobre o processo de desindustrialização na economia brasileira. A segunda seção tem por objetivo revisitar o conceito de desindustrialização. Do mesmo modo, a seção seguinte busca observar se os estados da região Sul sofrem de um processo de desindustrialização. Por fim, as considerações finais.

\section{0 debate da desindustrialização no Brasil}

A indústria de transformação da economia brasileira tem apresentado uma trajetória de perda de participação no PIB desde o início da década de 1980, quando detinha cerca de $32 \%$ do PIB. No entanto, essa participação caiu para $12 \%$ do PIB em 2014. Diante disso, diversos autores passaram a debater a existência de um processo de desindustrialização na economia brasileira.

Até o final da década de 1970, a política econômica no Brasil foi caracterizada por um processo de industrialização por substituição de importações. Primeiro de bens de consumo para, em seguida, desenvolver uma indústria de base. Dentro desse processo de industrialização, o Estado era a variável-chave tanto na produção como na geração de estímulos ao setor privado.

Contudo, diante do endividamento crescente dos países, essas políticas com forte presença do Estado passaram a ser substituídas por políticas liberais já no início da década de 
1980. Com efeito, ocorreu a abertura comercial e financeira da economia brasileira, e o Estado perdeu espaço para o mercado no que diz respeito à capacidade de induzir e coordenar os investimentos privados.

Segundo Hiratuka e Sarti (2015), isso culminou na deterioração da infraestrutura física e no atraso do avanço tecnológico. Para Arend e Fonseca (2012), até a década de 1980, a estrutura industrial da economia brasileira acompanhou o padrão internacional, mas, a partir dos anos 1980, a estrutura industrial do País perdeu dinamismo em relação à economia mundial. Ou seja, o processo de catching up que caracterizou a economia brasileira até a década de 1980 foi substituído por um processo de fall behind.

Portanto, não há discussão de que os anos 1980 são o "divisor de águas" na trajetória da indústria de transformação no Brasil. Porém, o que ocorreu com a indústria do País desses anos em diante é fonte de um intenso debate entre autores ortodoxos e heterodoxos. Esse debate se encontra longe de um consenso, não apenas entre autores de correntes econômicas diferentes, mas dentro da própria ortodoxia e heterodoxia.

Assim, os denominados novo-desenvolvimentistas defendem a hipótese de que a economia brasileira sofre de um processo de desindustrialização derivado à "doença holandesa", causada pela sobreapreciação real do câmbio. Segundo Oreiro e Feijó (2010) e Bresser-Pereira (2008), o aprofundamento da abertura comercial e financeira na economia brasileira, que teve início na década de 1980, combinado com o boom das commodities nos anos 2000, foi o principal responsável por essa sobreapreciação cambial.
Além disso, Nassif (2008), ao realizar uma análise da indústria de transformação por intensidade tecnológica, observou que ainda não ocorreu uma mudança da estrutura da indústria na direção dos setores intensivos em recursos naturais e, por isso, desconsidera a hipótese de desindustrialização para a economia brasileira.

No entanto, para Cano (2014), o Brasil sofre de um processo de desindustrialização devido: (a) a abertura comercial e financeira ilimitada; (b) o crescimento dos setores agrícola e mineral acima do da indústria de transformação, na última década; (c) a sobreapreciação cambial; (d) o baixo crescimento da economia internacional; (e) a alta taxa de juros; e (f) a redução dos investimentos interno e externo na indústria de transformação.

Todavia, Hiratuka e Sarti (2015) afirmam que existem transformações na estrutura produtiva global que ainda não receberam a devida atenção no debate sobre a desindustrialização no Brasil, como 1) a reorganização das estratégias globais da atividade produtiva por parte das empresas transnacionais, 2) a interferência da China não apenas nos preços das commodities, mas também nos preços dos bens industriais; 3) o aparecimento de novos competidores e a abertura de espaços seletivos para a inserção dos países em desenvolvimento nas redes de produção; e 4) o reforço de políticas nacionais dos países desenvolvidos, diante do cenário pós-crise, que objetivaram incentivar a mudança tecnológica e a reestruturação industrial como forma de recuperar o dinamismo econômico. Sendo assim, é necessário considerar esses aspectos para se ter uma análise mais pormenorizada do processo de desindustrialização na economia brasileira. 
Já, parte da ortodoxia, representada por Bonelli, Pessôa e Matos (2013), afirma que a desindustrialização no Brasil se trata, na verdade, de um ajustamento da estrutura industrial em relação à dotação de fatores da economia brasileira. Segundo os autores, o Brasil sofre, não de uma doença holandesa, mas de uma "doença soviética", ou seja, o padrão da indústria brasileira está muito acima do padrão internacional quando se considera o grau de desenvolvimento, população, nível tecnológico e recursos naturais. Em outras palavras, o Brasil possui um grau de industrialização muito acima do permitido por seus fatores de produção e, portanto, com uma participação no PIB superior ao nível considerado normal para uma economia em desenvolvimento. Sendo assim, o processo de desindustrialização deve ser entendido como um processo de ajuste, no sentido de estar convergindo para um nível adequado de desenvolvimento industrial, de modo que as políticas liberais são as principais responsáveis pelo padrão de normalidade da indústria nacional de acordo com a dotação dos fatores produtivos da economia brasileira.

Além disso, outros autores ortodoxos, como Barros e Pereira (2008), argumentam que o Brasil não padece de um processo de desindustrialização, mas atravessa um período de modernização da indústria propiciado pelo barateamento dos bens de capital importados que foram favorecidos pela sobreapreciação cambial. Diante disso, a desindustrialização pode ser entendida como um processo natural de seleção das atividades industriais, cuja perda de participação ocorre em atividades nas quais o País não possui vantagens comparativas.

Não obstante, a dimensão regional tem sido quase totalmente esquecida, ${ }^{1}$ tendo em vista a desindustrialização ser tratada como um processo homogêneo em todos os estados da federação. Contudo, isso não é verdade. A desindustrialização apresenta-se de forma diferenciada em todos os estados do País, de modo que é fundamental seu estudo em nível regional para compreender melhor esse processo e, assim, propor soluções adequadas a cada realidade econômica. Este será o objetivo do presente trabalho, mas antes é preciso conhecer o conceito de desindustrialização e suas adaptações ao nível de regiões e estados.

\section{Revisitando o conceito de desindustrialização}

A indústria de transformação é de suma importância para o crescimento econômico. Se a compararmos com os demais setores da economia, ela possui efeitos de encadeamentos tanto para frente quanto para trás. Para Hirschman (1958), os efeitos de encadeamento são os transbordamentos através de externalidades positivas para os demais setores que geram maior dinamismo na economia.

Além desses efeitos de encadeamentos, Kaldor (1957) também considera a indústria um setor diferencial em relação aos demais setores da economia, por possuir elevada produtividade e maiores economias estáticas e dinâmicas de escala, assim como maior capacidade de gerar crescimento e progresso tecnológico para toda economia e por aliviar as restrições externas ao crescimento, uma vez que os produtos industriais possuem alta elasticidade de renda da demanda. Devido a essas características, Kaldor (1967) observou que os países 
industrializados tendem a apresentar crescimento superior aos países cuja produção seja intensiva em recursos naturais.

Desse modo, a desindustrialização no sentido negativo do termo pode prejudicar o dinamismo da economia. No entanto, a desindustrialização nem sempre é ruim para a economia, representando, na verdade, um processo natural do desenvolvimento econômico. Portanto, é necessário definir a desindustrialização conceitualmente para que não ocorram erros de interpretação quando for realizada a análise para a economia da região Sul.

0 conceito de desindustrialização aparece, com maior evidência, no final da década de 1980, com o trabalho pioneiro de Rowthorn e Wells (1987), em que esses autores a definem como a redução da participação do emprego da indústria de transformação no emprego total. Para os autores em questão, existem pelo menos dois tipos de desindustrialização: a positiva e a negativa.

A desindustrialização positiva ocorre quando a perda de empregos se dá de forma relativa e absoluta, mas se trata de um processo natural do desenvolvimento econômico. Nesse caso, a indústria de transformação já é altamente produtiva, e, mesmo com a redução do emprego, tem-se um aumento da produção. No entanto, essa redução do emprego relativa e absoluta na indústria de transformação não provoca o aumento do desemprego, pois os trabalhadores da indústria de transformação que perderam seu emprego são deslocados para o setor de serviços. Desse modo, a economia encontra-se sempre em uma situação próxima do pleno emprego. Por isso, Rowthorn e Wells (ibid.) afirmam que a desindustrialização positiva não é um fenômeno patológico, mas um sintoma de sucesso econômico.

A desindustrialização negativa, por sua vez, é um fenômeno patológico que pode afetar uma economia em qualquer fase do desenvolvimento econômico. Nesse caso, o emprego ocioso gerado pela indústria de transformação não será absorvido pelo setor de serviços, de modo que o desemprego aumenta. Portanto, trata-se de um sintoma de fracasso econômico.

Não obstante, com o objetivo de incorporar os efeitos kaldorianos mencionados anteriormente, o conceito de desindustrialização foi redefinido por Tregenna (2009) no final da última década. Para a autora, a desindustrialização pode ocorrer tanto em termos de emprego como em termos de valor adicionado (V.A.). Assim, a desindustrialização pode ser conceituada como a perda de participação do emprego e/ou valor adicionado em relação a seus respectivos totais de forma permanente. Nesse caso, a desindustrialização será positiva se esse processo coincidir com um nível de renda per capita de país desenvolvido. E a desindustrialização será negativa se esse processo ocorrer antes que a economia alcance um nível de renda per capita de país desenvolvido. ${ }^{2}$

No entanto, esses conceitos foram definidos em nível de país, mas, como o propósito deste artigo, será analisar a situação da indústria da região Sul, é preciso adequar esses conceitos em nível regional e de estados. Embora seja possível encontrar alguns trabalhos sobre o processo de desindustrialização na perspectiva regional, o trabalho de Silva (2017) é pioneiro no sentido de buscar desenvolver 0 
conceito e as causas da desindustrialização regional e, ao mesmo tempo, permitir considerar a heterogeneidade do processo em nível de estados.

Silva (ibid.) adota a hipótese de que cada região apresenta um estado onde o processo de industrialização esteja avançado em relação aos demais estados da região e, por isso, denomina esse estado "avançado" e os demais, "estados atrasados". Além disso, o autor utiliza o termo (des)industrialização, com parênteses, pois é possível que, ao mesmo tempo que esteja ocorrendo um processo de desindustrialização no estado avançado, pode se ter um processo de industrialização nos demais estados.

Realizadas essas observações, ao relacionar a participação da indústria regional no PIB total da região com um processo de concentração/desconcentração da produção industrial nos estados, Silva (ibid.) mostra que pode acontecer três possibilidades de desindustrialização: a estagnada, a regressiva e a progressiva.

A (des)industrialização regional estagnada ocorre quando se têm mudanças de participação da indústria de cada estado no PIB industrial regional que provoquem a perda de participação da indústria de transformação da região no PIB regional, mas de modo que a participação da indústria regional no PIB industrial nacional permaneça sem grandes alterações. Esse conceito pode ser ampliado em uma versão positiva e outra negativa.

Quando a participação da indústria do estado atrasado apresenta aumento em detrimento da redução da participação industrial do estado avançado, tem-se uma (des)industrialização regional estagnada positiva. $\mathrm{Ou}$ seja, é positiva porque ocorre um processo de desconcentração da atividade industrial na região. No entanto, para ser positiva, a estrutura produtiva de ambos os estados não precisa ser modificada, mas o deslocamento da produção de bens que eram produzidos no estado avançado para o estado atrasado já é suficiente para ser enquadrado nessa definição.

Porém, quando a participação da indústria dos estados atrasados apresenta redução em detrimento do aumento da participação industrial do estado avançado, tem-se uma (des)industrialização estagnada negativa. $\mathrm{Ou}$ seja, negativa porque ocorre um processo de concentração da atividade industrial no estado avançado e, ao mesmo tempo, o aprofundamento das vantagens comparativas de cada estado. ${ }^{3}$ Nesse caso, as diferenças da estrutura produtiva dos estados não apenas são mantidas, mas aprofundadas.

No caso da (des)industrialização regional estagnada positiva, o estado avançado está se desindustrializando, e os estados atrasados estão se industrializando. No caso da (des)industrialização regional estagnada negativa, por sua vez, tem-se o processo inverso.

A (des)industrialização regional regressiva ocorre quando se têm mudanças de participação da indústria de cada estado no PIB industrial regional que resultam na queda de participação da indústria regional no PIB total da região e no PIB industrial nacional.

A (des)industrialização regional regressiva positiva pode ocorrer quando se tem um aumento de participação do estado atrasado no PIB da indústria regional pari passu com a redução da participação do estado avançado, de modo que isso implique um processo de desconcentração das atividades industriais na região. 
Já a (des)industrialização regional regressiva negativa ocorre quando a perda de participação da indústria regional no PIB da região for acompanhada de uma regressão da estrutura produtiva de ambos os estados, que provoque o aprofundamento da concentração das atividades industriais no estado avançado.

Não obstante, nesse caso, a estrutura produtiva do estado atrasado é orientada para a produção de bens nos quais possuem vantagens comparativas, enquanto a estrutura produtiva do estado industrializado é regredida em direção à produção de bens de baixo valor agregado, mas com valor agregado ainda superior ao dos estados atrasados.

A (des)industrialização regional progressiva, por seu turno, ocorre quando se têm mudanças de participação da indústria de cada estado que implique a redução da participação da indústria regional no PIB da região, acompanhada de aumento de participação em relação ao PIB industrial nacional.

Nesse caso, ocorre um processo de desconcentração da produção em nível nacional. No entanto, quando essa desconcentração implicar a desconcentração da produção industrial da região, tem-se um processo de (des) industrialização progressiva positiva. Caso contrário, se resultar na concentração da produção industrial no estado avançado, tem-se um processo de (des)industrialização progressiva negativa.

Já, no caso da (des)industrialização regional progressiva positiva, a estrutura produtiva do estado atrasado é orientada para a produção de bens com maior valor agregado, decorrente de um processo de desconcentração das atividades industriais, proporcionado apenas pela transferência de atividades do estado avançado para o estado atrasado, que, diante das vantagens apresentadas por este último estado, tem estímulos para aumentar a produção.

Cabe observar que o conceito de (des) industrialização regressiva possui certa correspondência com o conceito de desindustrialização precoce enquanto o conceito de desindustrialização progressiva tem semelhanças com o conceito de desindustrialização natural, visto anteriormente em nível nacional.

\section{A industrialização na região Sul}

A região Sul é composta pelos estados do Paraná, Santa Catarina e Rio Grande do Sul, sendo a atividade econômica desses estados, em seu início, essencialmente agrícola. No entanto, a necessidade provocou a gênese de algumas atividades produtivas que se tornou um processo de industrialização dos três estados diante de uma política nacional e regional de desenvolvimento econômico. Portanto, antes de analisarmos o processo de desindustrialização, é importante entender de forma sumária como foi a industrialização dos estados da região Sul.

A industrialização do Paraná até a década de 1930 estava relacionada com a produção do mate e da madeira que se destinava tanto ao mercado externo quanto ao mercado nacional, sendo sua forma de produção arcaica e de baixo nível tecnológico.

A partir de 1940, ocorreu um crescimento industrial, mas atrelado à produção do café, que foi realizada com a ocupação do Norte do Paraná, sendo considerada uma extensão da economia paulista. Assim, esse 
desenvolvimento industrial era mais provocado pela expansão da economia paulista do que propriamente por uma dinâmica local.

Com efeito, desenvolveu-se uma indústria de alimentos voltada para a demanda local, criada pela atividade cafeeira, sendo caracterizada pelo seu baixo nível tecnológico e pela reduzida economia de escala. Além disso, havia uma infraestrutura precária no que diz respeito a transporte e energia. Esse modelo de desenvolvimento industrial permaneceu até a década de 1960.

Não obstante, essa situação começou a mudar a partir da crise da economia cafeeira no final da década de 1950, de modo que era necessário encontrar outras formas de desenvolvimento para o estado do Paraná. Paralelamente a isso, o Estado brasileiro passou a ter maior presença na economia, com o objetivo de eliminar os estrangulamentos do desenvolvimento econômico brasileiro. Como havia certo consenso de que o atraso do Paraná estava relacionado a sua condição de produtor de bens primários, a opção do governo paranaense foi a via da industrialização.

Diante disso, o governo do Paraná assumiu duas linhas de desenvolvimento. Primeiro, no sentido de eliminar as deficiências de infraestrutura e propiciar a possibilidade de maior rentabilidade ao capital investido. Segundo, como financiador das empresas industriais.

Assim, em 1962, foi criada pelo estado do Paraná a Companhia de Desenvolvimento do Paraná (Copedar) e o Banco de Desenvolvimento do Paraná (Badep). A criação da Copedar e do Badep foi estratégica, uma vez que a primeira instituição tinha por objetivo aumentar a rentabilidade da atividade industrial através de uma infraestrutura adequada, e o Badep visava ao financiamento para as indústrias que se instalassem no Paraná.

Assim, a indústria incipiente e de baixa intensidade tecnológica da época do café foi perdendo espaço para a indústria de bens com maior valor agregado e intensivo em capital. Com efeito, ocorreu a consolidação da Cidade Industrial de Curitiba (CIC), que foi o principal projeto executado pela política industrial do estado e que permitiu realizar uma agressiva política de atração de investimentos.

Todavia, a atração desses investimentos se dava em decorrência da infraestrutura básica, dos incentivos fiscais e das economias de aglomeração existentes na capital do estado. Além disso, o interior do estado não apresentava as mesmas condições para atrair os investimentos industriais, o que, de certo modo, gerou um processo de industrialização concentrado no entorno da capital paranaense, restando, ao interior, às indústrias ligadas à agropecuária. ${ }^{4}$

Em 1970 Curitiba já concentrava 28\% de toda a produção industrial do estado, percentual que foi aumentando na década de 1980 para quase $53 \%$ com a instalação de indústrias com maior valor agregado, como a metal-mecânica e a indústria química. No início dos aos 2000, esse percentual já era maior que $60 \%$.

Quanto ao estado de Santa Catarina, o processo de industrialização visava atender a demanda local, mas terminou por atender ao mercado nacional e também ao mercado externo. Entre os principais setores da indústria catarinense se apresentam a indústria de alimentos, têxtil, metal-mecânico, moveleiro e a indústria de cerâmica. Essas atividades tiveram início em meados do século $X X$ tendo uma contribuição fundamental dos imigrantes, 
sobretudo, alemães e italianos. Contudo, tais atividades passaram a ser intensificadas somente a partir da década de 1940 com o projeto de industrialização nacional e pós-1960 com a implementação do Plano de Metas no Brasil.

Com a política nacional de substituição de importações ocorreu um desenvolvimento maior da indústria paulista que passou a integrar a economia brasileira, gerando efeitos de transbordamentos, sobretudo, para os estados próximos de São Paulo como os da região Sul.

Com efeito, a indústria catarinense tirou proveito dessa proximidade e rapidamente se adaptou à demanda da economia paulista, fornecendo alimento, vestuário e carvão mineral. No entanto, somente após 1945, a estrutura industrial de Santa Catarina passou por um processo mais intenso de diversificação e ampliação de setores, como o de papel e papelão, pasta mecânica (resultado da diversificação do complexo madeireiro), têxtil e carbonífero, que tiveram sua produção ampliada com a criação de novas indústrias. Nesse período também ocorreu a criação de novos setores, como o cerâmico, plástico, metal-mecânico, materiais elétricos e de indústrias ligadas ao setor de transporte. Além disso, ocorreu a industrialização da agricultura, que se transformou em um complexo agroindustrial.

No entanto, esse avanço da industrialização em Santa Catarina esbarrava nas deficiências de infraestrutura do estado, como a falta de energia, recursos financeiros, transporte rodoviário e de portos. Contudo, somente em meados da década de 1960, com a implementação do Plano de Metas, essas barreiras começam a ser resolvidas. Como essas deficiências de infraestrutura eram uma característica de praticamente todos os estados da federação, o Estado brasileiro passou a intervir, fornecendo crédito, investimentos no setor elétrico e no setor de transportes.

No que diz respeito às dificuldades de crédito, foi criado o Banco de Desenvolvimento do Estado de Santa Catarina (BDE), o Banco Regional de Desenvolvimento do Extremo Sul (BRDE), o Fundo de Desenvolvimento de Santa Catarina (Fundesc), o Programa de Apoio à Capitalização de Empresas (Procape), o Programa de Desenvolvimento da Empresa Catarinense (Prodec) e o Programa de Fomento de Santa Catarina (Badesc). Nos anos 1970, essa política continuou com o Projeto Catarinense de Desenvolvimento (PCD) e com o Programa de Governo de Antônio Carlos Konder Reis. Com efeito, diante de tudo isso, ocorreram a consolidação e a integração da indústria catarinense à economia nacional e internacional.

Não obstante, todo esse aparato de desenvolvimento econômico foi ser perdendo ao longo dos anos 1980 e 1990, devido ao retorno das políticas liberais que provocaram mudanças estruturais significativas na indústria catarinense. Segundo Goulart Filho (2002), é nesse período que ocorrem a redução das atividades estatais, a reestruturação da indústria cerâmica, o desmonte do setor carbonífero, a reestruturação patrimonial no complexo eletro-metal-mecânico e no complexo agroindustrial, a desverticalização e a retração no segmento têxtil-vestuário e a desnacionalização no complexo agroindustrial.

Já a industrialização no Rio Grande do Sul teve início a partir da acumulação de capital proporcionada pela principal atividade da época, a pecuária. Essa indústria se caracterizou pela produção de bens de consumo não duráveis, pelo aproveitamento das matérias-primas 
locais e pela produção de equipamentos e insumos para o setor agropecuário. Assim, desde o início, a indústria do Rio Grande do Sul mantinha estreita relação com a agropecuária.

A industrialização no estado gaúcho foi beneficiada pelas dificuldades portuárias que havia nos primeiros anos do século XX, uma vez que a dificuldade de acesso ao estado proporcionou certo isolamento do Rio Grande do Sul em relação à concorrência da indústria do restante do País e do exterior. Portanto, os fatores de produção tinham que ser locais, assim como o mercado de consumo.

Dada essa característica da economia gaúcha de produzir para o mercado interno e sua relação com o setor agrícola, a indústria do Rio Grande do Sul ficou caracterizada, até a década de 1950, pela produção de bens de consumo não duráveis, pelo aproveitamento de matéria-prima local e pelo fornecimento de máquinas, equipamentos e insumos ao setor agrícola.

No entanto, com a maior integração espacial e econômica entre as regiões e estados do País, que ocorreu depois da década de 1950, essa vantagem locacional foi praticamente eliminada, e a indústria gaúcha passou a sofrer com a concorrência dos produtos industriais de outros estados nos mercados locais, o que gerou transformações expressivas na estrutura produtiva da indústria do estado.

A indústria gaúcha não estava preparada para essa maior integração geográfica e econômica, uma vez que, em relação à indústria paulista, a indústria do Rio Grande do Sul era defasada tecnologicamente, com baixa escala de produção, com formas arcaicas de produção e comercialização, com deficiência de infraestrutura básica e energética. Tudo isso contribuiu para a perda de competividade da indústria gaúcha no mercado local e nos mercados externos; ela foi paulatinamente perdendo espaço nesses mercados para os produtos da indústria paulista.

Tudo isso gerou uma crise na economia gaúcha. Em meados dos anos 1960, ocorreu um intenso debate em torno do tipo de industrialização que o Rio Grande do Sul deveria realizar. Assim, foi decidido que o estado deveria desenvolver um polo industrial dinâmico, mas sem descuidar da indústria que utilizava as matérias-primas locais.

Pelo lado da infraestrutura e do fornecimento de crédito, houve a criação do $B R D E$, a criação do Conselho de Desenvolvimento do Extremo Sul (Codesul), o aumento de recursos derivados do então Banco Nacional de Desenvolvimento Econômico (BNDE) que, juntos, permitiram reduzir alguns gargalos em relação à região Sudeste.

Diante disso, a indústria do Rio Grande do Sul apresentou forte crescimento na década seguinte, sobretudo, as indústrias mais dinâmicas. Esse crescimento da indústria gaúcha também foi impulsionado, em parte, pelo crescimento da inovação no campo que buscava aumentar a produtividade para a exportação e, portanto, demandou mais máquinas, equipamentos, insumos agrícolas, produtos químicos e novas técnicas de plantio. Do mesmo modo, o crescimento da indústria gaúcha foi em parte provocado pelo crescimento da indústria paulista, que também demandou bens intermediários da indústria gaúcha.

Nos anos 1990, com a abertura comercial e a valorização do Real, aumentou a concorrência dos produtos importados no País e, sobretudo, no Rio Grande do Sul, em decorrência 
de sua indústria ser fortemente ligada à agropecuária a jusante e a montante, principalmente nos setores exportadores. ${ }^{5}$ Diante disso, as indústrias gaúchas passaram a adotar estratégias com o objetivo de aumentar a produtividade e se tornar mais competitivas diante dos importados.

Não obstante, a partir de 1999, com a desvalorização cambial e o surgimento da forte demanda da China, deu-se início a um novo ciclo de crescimento das exportações de commodities relacionadas com a indústria gaúcha. Diante disso, o Rio Grande do Sul tornou-se o terceiro maior exportador do País nos anos 2000, ficando atrás apenas de São Paulo e de Minas Gerais.

Contudo, como visto, desde o início, a dinâmica industrial da região Sul tornou-se dependente do setor primário, sendo este, por sua vez, dependente da dinâmica da economia brasileira, sobretudo, da economia paulista e dos mercados externos. Portanto, a indústria sulista tornou-se, também, dependente desses mercados. Em outras palavras, a dinâmica da indústria da região Sul encontra-se fortemente relacionada com o movimento da taxa de câmbio, do PIB dos principais importadores e dos preços internacionais das commodities, bem como do crescimento da economia brasileira.

Todavia, como será que se comportou a indústria desses estados no período 20022014? Será que esses estados continuaram aprofundando seu processo de industrialização? E quanto à concentração da produção e do emprego industrial, ocorreu alguma inflexão? A explicação para essas perguntas será encontrada a partir da metodologia de Silva (2017), cujos resultados serão analisados na próxima seção.

\section{A (des)industrialização na região Sul}

Descrito como ocorreu o processo de industrialização dos estados da região Sul, esta seção tem por objetivo verificar o comportamento da indústria na região no período 2002-2014, com o propósito de observar a ocorrência ou não da desindustrialização. Para isso, será utilizada a metodologia de Silva (2017), segundo a qual o Rio Grande do Sul será considerado o estado avançado em seu processo de industrialização em relação aos demais estados da região.

A análise dos indicadores clássicos da desindustrialização para a indústria de transformação do Brasil, Gráficos 1 e 2, mostra que ocorreu uma perda de participação em termos de emprego de 2,3 p.p. no período 2007-2014. No mesmo sentido, a indústria de transformação nacional apresentou uma perda de 5,8 p.p. em termos de produção no período 2004-2014. Essas perdas de participação mostram que existe um processo de desindustrialização na indústria brasileira.

No entanto, da perda de 2,3 p.p. que a indústria brasileira apresentou em termos de emprego, a região Sul foi responsável por 0,5 p.p. enquanto as demais regiões foram responsáveis por 1,8 p.p. Em relação à perda de 5,8 p.p., em termos de produção, a região Sul foi responsável por 1,0 p.p. enquanto as demais regiões foram responsáveis por 4,8 p.p. Portanto, a região Sul foi responsável por parte considerável da perda de dinamismo industrial no País, mais especificamente por $22 \%$ e $17 \%$ da perda total apresentada pela indústria brasileira em termos de emprego e produção respectivamente. 
Gráfico 1 - Participação do emprego da indústria de transformação da região Sul e do Brasil no emprego total do Brasil: 2002-2014

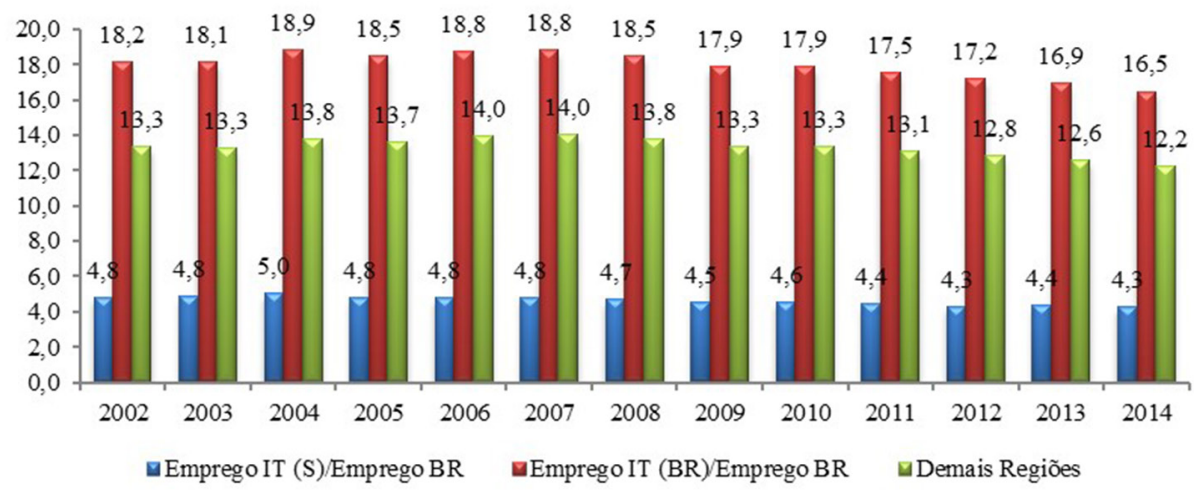

Fonte: elaboração própria a partir dos dados da Rais (2019).

Gráfico 2 - Participação da produção da indústria de transformação da região Sul e do Brasil no PIB do Brasil: 2002-2014.

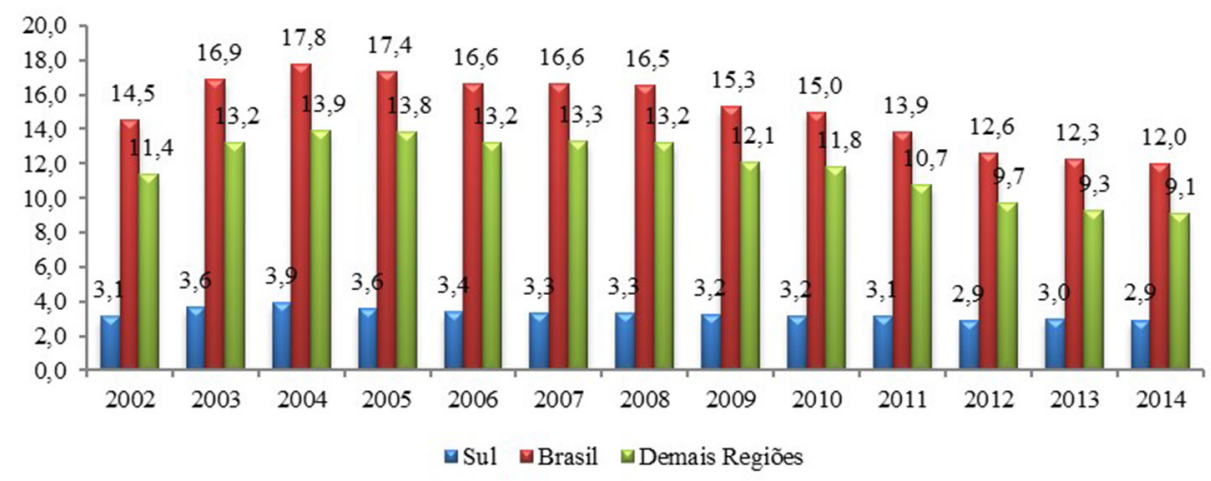

Fonte: elaboração própria, a partir dos dados das Contas Regionais IBGE (2019). 


\section{Gráfico 3 - Participação da indústria de transformação (IT) da região Sul no PIB e no emprego total da região Sul (S): 2002-2014.}

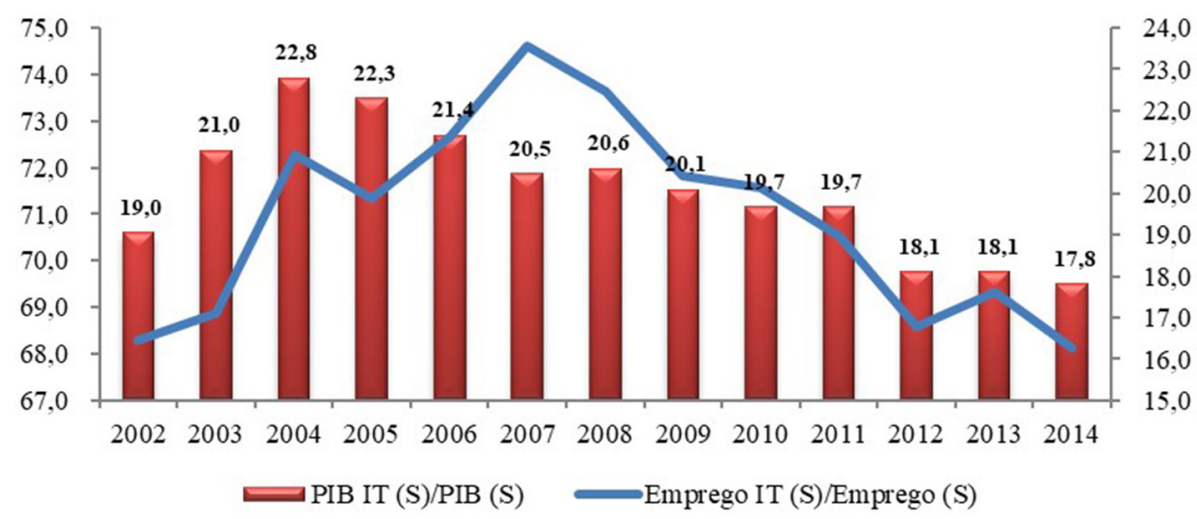

Fonte: elaboração própria, a partir dos dados das Contas Nacionais (IBGE, 2019) e da Rais (2019).

Todavia, a dinâmica do emprego industrial na região Sul está, de certa forma, relacionada com a dinâmica na produção, uma vez que se observa uma forte relação entre o emprego e a produção da indústria de transformação na região sulista.

Quando a análise dos indicadores clássicos para a indústria da região em foco é realizada considerando-se o PIB e o emprego totais da região Sul (Gráfico 3), observa-se uma trajetória de declínio em ambos os indicadores. Em 2004, a indústria de transformação sulista era responsável por $22,8 \%$ do PIB regional (eixo direito do Gráfico 3) e passou para 17,8\% em 2014, gerando uma perda de 5,0 p.p. no período em foco. Em relação à participação do emprego industrial no emprego total da região (eixo esquerdo do Gráfico 3) também se observa uma perda, passando de 74,6\%, em 2007, para $68,1 \%$, em 2014 , uma perda de 6,5 p.p. nesse período.
Portanto, há sinais efetivos de que a indústria de transformação da região Sul tem sofrido de um processo de desindustrialização regional. Contudo, qual a contribuição de cada estado nesse processo de desindustrialização regional? Será que algum estado seguiu na via contrária, isto é, deu continuidade no seu processo de industrialização?

Na Tabela 1, pode ser observado que em 2004, quando a indústria sulista alcançou seu ápice em termos de participação na produção no PIB regional, ou seja, 22,8\%, os estado de Santa Catarina, Paraná e Rio Grande do Sul foram responsáveis por 6,1 p.p., 7,9 p.p. e 8,9 p.p. desse total apresentado pela região. Já a Tabela 2 mostra a contribuição de cada estado no processo de desindustrialização da região Sul em termos de emprego, de modo que, em 2007, quando a região apresentou seu maior percentual $(74,6 \%)$ no período analisado, o estado do Rio Grande do Sul já vinha 
apresentando dificuldades desde 2004. Além disso, os demais estados estavam aumentando suas participações no emprego total da região. Contudo, apesar de uma inflexão nesse ganho de participação do emprego destes últimos dois estados, em 2014 eles ainda possuíam participações superiores às apresentadas em 2002, o mesmo não ocorrendo com o estado do Rio Grande do Sul.
No entanto, depois da crise financeira internacional de 2008-2009, as indústrias desses estados passaram por dificuldades, refletindo-se nos indicadores anteriormente analisados, de modo que a participação da indústria de cada estado no PIB regional caiu em 2014. A participação de Santa Catarina passou para 5,6 p.p., a do Paraná passou para 5,8 p.p. e a do Rio Grande do Sul passou para 6,4 p.p.,

Tabela 1 - Participação do PIB da indústria de transformação dos estados no PIB da região Sul: 2002-2014

\begin{tabular}{l|r|r|r|r|r|r|r|r|r|r|r|r|r}
\hline & 2002 & 2003 & 2004 & 2005 & 2006 & 2007 & 2008 & 2009 & 2010 & 2011 & 2012 & 2013 & 2014 \\
\hline Santa Catarina & 5,4 & 5,5 & 6,1 & 6,2 & 6,2 & 6,0 & 6,1 & 5,4 & 5,5 & 5,9 & 5,7 & 5,2 & 5,6 \\
Paraná & 6,0 & 7,3 & 7,9 & 7,5 & 7,4 & 7,1 & 6,9 & 6,8 & 6,4 & 6,5 & 5,6 & 6,2 & 5,8 \\
Rio Grande do Sul & 7,6 & 8,2 & 8,9 & 8,5 & 7,8 & 7,3 & 7,5 & 7,9 & 7,8 & 7,3 & 6,9 & 6,6 & 6,4 \\
\hline Região Sul & 19,0 & 21,0 & 22,8 & 22,3 & 21,4 & 20,5 & 20,6 & 20,1 & 19,7 & 19,7 & 18,1 & 18,1 & 17,8 \\
\hline
\end{tabular}

Fonte: elaboração própria, a partir dos dados das Contas Regionais IBGE (2019).

Tabela 2 - Participação do Emprego da Indústria de transformação dos estados no Emprego total da região Sul: 2002-2014

\begin{tabular}{l|c|c|c|c|c|c|c|c|c|c|c|c|c}
\hline & 2002 & 2003 & 2004 & 2005 & 2006 & 2007 & 2008 & 2009 & 2010 & 2011 & 2012 & 2013 & 2014 \\
\hline Santa Catarina & 20,5 & 20,6 & 21,8 & 22,1 & 22,9 & 23,5 & 23,1 & 22,5 & 22,5 & 22,1 & 21,4 & 22,1 & 22,0 \\
Paraná & 20,2 & 20,8 & 22,0 & 22,2 & 23,0 & 24,1 & 24,1 & 23,8 & 23,5 & 23,2 & 22,7 & 23,0 & 22,6 \\
Rio Grande do Sul & 27,6 & 27,5 & 28,4 & 27,0 & 26,8 & 27,0 & 26,4 & 25,5 & 25,6 & 25,3 & 24,5 & 24,2 & 23,5 \\
\hline Região Sul & 68,3 & 68,9 & 72,3 & 71,3 & 72,7 & 74,6 & 73,6 & 71,8 & 71,6 & 70,5 & 68,6 & 69,3 & 68,1 \\
\hline
\end{tabular}

Fonte: elaboração própria, a partir dos dados da RAIS (2019). 
constituindo uma participação total da região de apenas 17,8\% em 2014. Em relação à participação do emprego no emprego total da região (Tabela 2), a perda concentrou-se, sobretudo, no estado do Rio Grande do Sul, que passou de 28,4 p.p., em 2004, para 23,5 p.p., em 2014.

Assim, é possível observar que a desindustrialização na região Sul se deve, sobretudo, ao desempenho da indústria de transformação do estado do Rio Grande do Sul, dado que a participação da indústria do estado de Santa Catarina e do Paraná apresentou uma leve queda que se deve mais à conjuntura no período analisado do que a uma mudança estrutural em suas respectivas indústrias de transformação. Além disso, os indicadores analisados da indústria de transformação do Rio Grande do Sul sinalizam que pode estar em curso uma mudança estrutural nesse estado.
Mas esse processo pode ser caracterizado como estagnado, regressivo ou progressivo? Para isso, é preciso analisar a evolução da participação da indústria de transformação sulista no PIB e no emprego industrial do Brasil, o que pode ser visto no Gráfico 4.

Em termos de emprego, ocorreu uma tendência de perda de participação até o ano de 2012, quando se iniciou uma recuperação. Contudo, a participação do emprego em 2014 foi menor do que a de 2004, quando teve início o declínio desse indicador. Mas, quando considerada a produção industrial, a região Sul obteve um ganho de participação expressivo entre 2007 e 2014, cerca de 4,3 p.p.

Dessa forma, observa-se um processo de desindustrialização regional progressivo na região Sul, uma vez que a desindustrialização na região foi acompanhada de um ganho de participação na indústria nacional.

\section{Gráfico 4 - Participação da produção e do emprego da indústria de transformação da região Sul na produção e emprego da indústria de transformação do Brasil: 2002-2014}

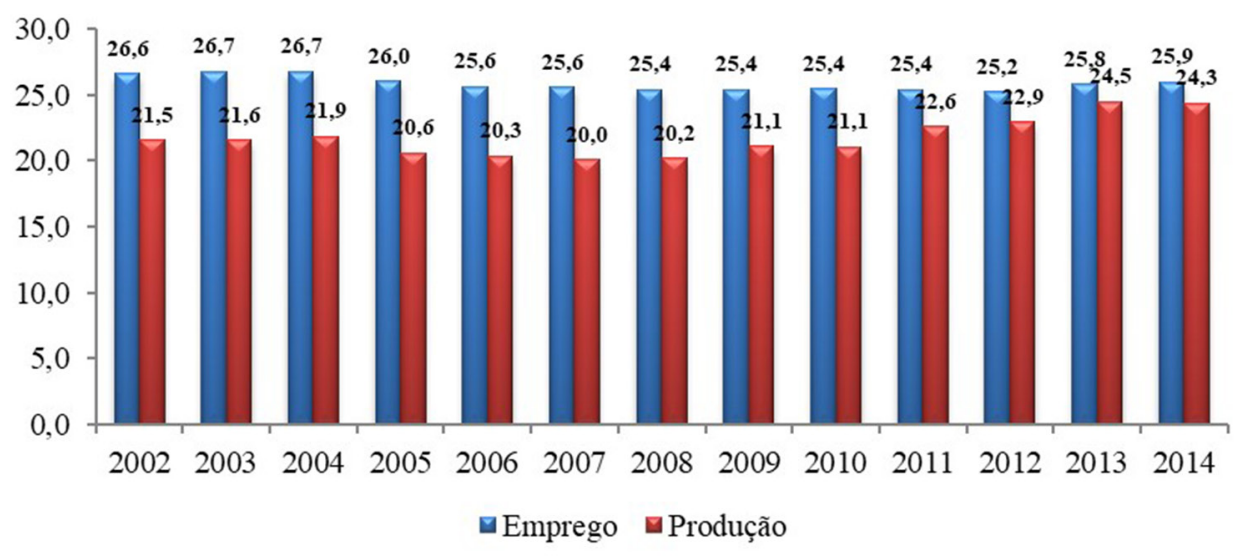

Fonte: elaboração própria, a partir dos dados das Contas Nacionais (IBGE) e da Rais (2019). 
Não obstante, é preciso analisar a composição da indústria entre os estados para poder caracterizar a desindustrialização como progressiva positiva ou progressiva negativa. Isto é, será que o processo de desindustrialização foi seguido de uma desconcentração da produção e do emprego industrial na região Sul? A resposta pode ser encontrada na análise das Tabelas 3 e 4.

Com efeito, observa-se uma desconcentração da produção e do emprego entre os estados da região Sul, já que, enquanto a indústria do estado do Rio do Grande do Sul apresentou uma perda considerável de participação na produção e no emprego regional, os estados do Paraná e de Santa Catarina apresentaram um aumento de participação.

Enquanto a participação da produção em Santa Catarina passa de $28,4 \%$ para $31,3 \%$ e a participação do emprego passa de $30 \%$ para $32 \%$ em relação à indústria regional no período 2002-2014, o estado do Paraná teve um ganho de 1,0 p.p. em termos de produção e de quase 4,0 p.p. em termos de emprego. Já, o estado do Rio Grande do Sul teve uma perda de participação de produção de 4,0 p.p. e de quase 6,0 p.p. em termos de emprego no período 2002-2014.

Tabela 3 - Distribuição da produção da indústria de transformação dos estados da região Sul: 2002-2014

\begin{tabular}{l|r|r|r|r|r|r|r|r|r|r|r|r|c}
\hline & 2002 & 2003 & 2004 & 2005 & 2006 & 2007 & 2008 & 2009 & 2010 & 2011 & 2012 & 2013 & 2014 \\
\hline Santa Catarina & 28,4 & 26,2 & 26,7 & 27,9 & 29,0 & 29,4 & 29,7 & 27,0 & 28,0 & 29,8 & 31,2 & 29,0 & 31,3 \\
Paraná & 31,8 & 34,8 & 34,5 & 33,8 & 34,6 & 34,8 & 33,7 & 33,6 & 32,5 & 32,9 & 30,8 & 34,4 & 32,8 \\
Rio Grande do Sul & 39,9 & 39,0 & 38,8 & 38,3 & 36,4 & 35,7 & 36,6 & 39,4 & 39,5 & 37,3 & 37,9 & 36,7 & 35,9 \\
\hline
\end{tabular}

Fonte: elaboração própria, a partir dos dados das Contas Regionais IBGE (2019).

Tabela 4 - Distribuição do emprego da indústria de transformação dos estados da região Sul: 2002-2014

\begin{tabular}{l|r|r|r|r|r|r|r|r|r|r|r|r|c}
\hline & $\mathbf{2 0 0 2}$ & $\mathbf{2 0 0 3}$ & $\mathbf{2 0 0 4}$ & $\mathbf{2 0 0 5}$ & $\mathbf{2 0 0 6}$ & $\mathbf{2 0 0 7}$ & $\mathbf{2 0 0 8}$ & $\mathbf{2 0 0 9}$ & $\mathbf{2 0 1 0}$ & $\mathbf{2 0 1 1}$ & $\mathbf{2 0 1 2}$ & $\mathbf{2 0 1 3}$ & $\mathbf{2 0 1 4}$ \\
\hline Santa Catarina & 30,1 & 29,9 & 30,2 & 30,9 & 31,5 & 31,5 & 31,3 & 31,3 & 31,4 & 31,3 & 31,2 & 31,8 & 32,3 \\
Paraná & 29,5 & 30,1 & 30,5 & 31,1 & 31,6 & 32,4 & 32,8 & 33,2 & 32,8 & 32,9 & 33,0 & 33,2 & 33,2 \\
Rio Grande do Sul & 40,4 & 39,9 & 39,3 & 37,9 & 36,9 & 36,2 & 35,9 & 35,5 & 35,8 & 35,8 & 35,7 & 34,9 & 34,5 \\
\hline
\end{tabular}

Fonte: elaboração própria a partir dos dados da Rais (2019). 
Portanto, trata-se de um processo de desindustrialização progressivo e positivo, uma vez que a desindustrialização na região Sul foi seguida de um ganho de participação na indústria de transformação nacional e de um processo de desconcentração da produção e do emprego do estado do Rio Grande do Sul para os estados do Paraná e, sobretudo, de Santa Catarina.

Esse processo de desindustrialização acentuado no Rio Grande do Sul deve-se ao fato de a indústria de transformação desse estado ser mais sensível a taxa de câmbio, a crises externas e a perda de dinamismo da economia brasileira do que a indústria dos demais estados da região. A taxa de câmbio ficou sobreapreciada no período 2004-2010, gerando um processo de substituição da produção nacional por importados. Quando a taxa de câmbio voltou a ficar depreciada, a crise externa e a desaceleração da economia brasileira pós-2010 não permitiram uma recuperação da indústria gaúcha. Combinado a isto, os preços das commodities também caíram com a desaceleração da China no mesmo período. Como a indústria gaúcha está relacionada com o setor agrícola, essa desaceleração gerou uma queda na demanda por máquinas e equipamentos agrícolas, o que afetou fortemente a indústria de bens de capital.

\section{Considerações finais}

Este artigo teve por objetivo analisar a evolução da indústria de transformação na região Sul no período 2002-2014, com o propósito de observar a existência de um processo de desindustrialização.
Para isso, foi utilizada a metodologia de Silva (2017), segunda a qual o processo de desindustrialização regional pode ser de três tipos: regressiva, estagnada e progressiva. No caso da existência de um processo de desindustrialização e se este for acompanhado de um processo de desconcentração da produção e/ou do emprego, tem-se uma desindustrialização positiva. Caso contrário, tem-se um processo negativo.

Mas, antes de analisar os dados, foi realizada uma breve descrição da formação da indústria nos estados do Rio Grande do Sul, Santa Catarina e do Paraná. Na qual foi verificado que a indústria da região está ligada ao setor agrícola, à economia doméstica e à economia externa.

Em seguida, a análise dos dados mostrou a existência de um processo de desindustrialização progressiva positiva na região Sul, uma vez que a perda de participação dos indicadores do emprego e da produção foi acompanhada de um ganho de participação na indústria nacional e da desconcentração da produção do estado avançado (Rio Grande do Sul) para os estados atrasados (Paraná e Santa Catarina).

No entanto, este trabalho não esgota 0 tema, mas abre espaço para uma discussão maior, de modo que novos trabalhos possam ser desenvolvidos no sentido de observar se o processo de desconcentração da produção e do emprego industrial na região Sul tem beneficiado as capitais dos estados, isto é, analisar a distribuição do emprego e da produção entre as microrregiões da região Sul. Uma análise estadual do processo de desindustrialização também pode ser desenvolvida, assim com uma análise desagregada por intensidade tecnológica da indústria de transformação para cada estado. 


\section{[I] http://orcid.org/0000-0002-1514-6999}

Universidade Federal Rural do Semi Árido, Departamento de Engenharias, campus Angicos. Mossoró, RN/Brasil.

josealderir16@hotmail.com

\section{Notas}

(1) Exceto por alguns raros trabalhos como Sampaio (2015), Spindola e Lima (2014), Botelho, Sousa e Avellar (2014) Pereira e Cairo (2016) e Filho (2016).

(2) Para uma revisão conceitual sobre a desindustrialização, vide Silva e Lourenço (2014); e para, uma crítica aos indicadores clássicos, vide Silva e Lourenço (2016).

(3) Partindo da hipótese de que os estados atrasados e desenvolvidos apresentam, respectivamente, vantagens comparativas na produção de bens pouco e muito intensivo em capital.

(4) Vide Trintin (2006) e Barbosa, Carmo e Raiker (2015).

(5) Vide Calandro e Campos (2004).

\section{Referências}

AREND, M. e FONSECA, P. C. D. (2012). Brasil (1955-2005): 25 anos de catching up, 25 anos de falling behind. Revista de Economia Política, v. 32, n. 1, pp. 33-54.

BARBOSA, W.; CARMO, A. S. S. e RAIHER, A. P. (2015). Existe desindustrialização no Estado do Paraná? Um teste empírico para o período de 1996 a 2012. Informe Gepec. Toledo, v. 19, n. 1, pp. 55-79.

BARROS, O. e PEREIRA, R. R. (2008). "Desmistificando a tese de desindustrialização: reestruturação da indústria brasileira em uma época de transformações globais”. In: BARROS, O. e GIAMBIAGI, F. (orgs.). Brasil globalizado: o Brasil em um mundo surpreendente. Rio de Janeiro, Elsevier, pp. 299-330.

BONELLI, R.; PESSÔA, S. e MATOS, S. (2013). “Desindustrialização no Brasil: fatos e interpretação”. In: BACHA, E. e BOLLE, M. (eds.). O futuro da indústria no Brasil: desindustrialização em debate. Rio de Janeiro, Civilização Brasileira, pp. 45-80.

BOTELHO, M. R.; SOUSA, G. F. e AVELLAR, A. P. M. (2014). A incidência desigual do processo de desindustrialização nos estados brasileiros. In: XVI SEMINÁRIO DE DIAMANTINA. Anais... Diamantina, MG. 
BRESSER-PEREIRA, L. C. (2008). The Dutch disease and its neutralization: a Ricardian approach. Revista de Economia Política, São Paulo, v. 28, n. 1, pp. 47-71.

CALANDRO, M. L. e CAMPOS, S. H. (2004). Dez anos de Plano Real e a indústria gaúcha. Indicadores Econômicos FEE, v. 32, n. 2, pp. 247-273.

CANO, W. (2014). (Des)Industrialização e (Sub)Desenvolvimento. Cadernos do Desenvolvimento. Rio de Janeiro, v. 9, n. 15, pp. 139-174.

FILHO, R. B. (2016). Dinâmica industrial: evidências para o Brasil e para as regiões Sudeste e Sul. Ensaios FEE, v. 37, n. 3, pp. 739-768.

GOULART FILHO, A. G. (2002). A formação econômica de Santa Catarina. Revista Ensaios FEE. Porto Alegre, v. 23, n. 2, pp. 977-1007.

HIRATUKA, C. e SARTI, F. (2015). Transformações na estrutura produtiva global, desindustrialização e desenvolvimento industrial no Brasil: uma contribuição ao debate. Campinas, IE Unicamp (Texto para Discussão, n. 255).

HIRSCHMAN, A. O. (1958). The strategy of economic development. New Haven, Yale University Press.

IBGE - INSTITUIO BRASILEIRO DE GEOGRAFIA E ESTATÍSTICA (2018). Contas Nacionais e Regionais. Disponível em: <http://www.ibge.gov.br>. Acesso em: abr 2019.

KALDOR, N. (1957). A Model of Economic Growth. The Economic Journal. Oxford, Oxford University Press, v. 67, n. 268, pp. 591-624.

(1967). "Problems of industrialization in underdeveloped countries". In: KALDOR, N. Strategic Factors of Economic Development. Nova York, Cornell University Press.

NASSIF, A. (2008). Há evidências de desindustrialização no Brasil. Revista de Economia Política, São Paulo, v. 28, n. 1, pp. 72-96.

OREIRO, J. L. e FEIJÓ, C. (2010). Desindustrialização: conceituação, causas, efeitos e o caso brasileiro. Revista de Economia Política. São Paulo, v. 30, n. 2, pp. 219-232.

PEREIRA, W. M. e CAIRO, S. A. F. (2016). Desindustrialização e mudança estrutural na região sudeste: um estudo comparado. In: 1ㅇ ENCONTRO DA NACIONAL DE ECONOMIA INDUSTRIAL E INOVAÇÃO. Anais... Araraquara, SP, pp. 372-390.,

RAIS - RELAÇÃO ANUAL DE INFORMAÇÕES SOCIAIS (2018). Disponível em: <http://bi.mte.gov.br/ scripts10/dardoweb.cgi>. Acesso em: abr. 2019.

ROWTHORN, R. e WELLS, J. (1987). De-industrialisation and Foreign Trade. Cambridge University Press.

SAMPAIO, D. P. (2015). Desindustrialização e Estruturas Produtivas Regionais no Brasil. Tese de Doutorado. Campinas, Universidade Estadual de Campinas.

SILVA, J. A. e LOURENÇO, A. L. C. (2014). Revisitando o conceito de Desindustrialização. Oikos. Rio de Janeiro, v. 13, pp. 57-73.

(2016). Críticas e contribuições aos indicadores usuais da desindustrialização. Pesquisa \& Debate, São Paulo, v. 27, pp. 45-62.

SILVA, J. A. (2017). Desindustrialização regional: conceitos, causas, efeitos e o caso brasileiro. Mimeo. 
SPINDOLA, F. D. e LIMA, J. P. R. (2014). Desindustrialização Regional no Brasil. In: III ENCONTRO PERNAMBUCANO DE ECONOMIA. Anais... Recife.

TREGENNA, F. (2009). Characterizing deindustrialization: an analysis of changes in manufacturing employment and output internationally. Cambridge Journal of Economics. Oxford, UK, v. 33, n. 3, pp. 433-466.

TRINTIN, J. G. (2006). A nova economia paranaense: 1970-2000. Maringá, Eduem, 190p.

Texto recebido em $27 / \mathrm{fev} / 2018$

Texto aprovado em 30/jul/2018 